\title{
In the Face of an Emergency: What Makes a Responsive and Resilient Society?
}

\author{
by Montine L. Walters \\ Olympic Resilience Officer, Greater London Authority.
}

\section{Introduction}

T his article intends to highlight the ways in which the response required to deal with terrorist threats of the 21 st Century differs from that required to respond to threats the UK has faced in the past. In addition it will assess ways in which the UK may strengthen the population's resilience and the ability of the population to respond to emergency incidents.

The response of the crowd following a suicide bomb attack, including the ability of the spontaneous competent 'zero' responders to emerge from within the crowd prior to the arrival of professional first responders at the incident scene, helps build resilience. Responding to an emergency is time sensitive, therefore whilst waiting for the professional responders to arrive at the site and if necessary, receive safety clearance, the time taken to reach the casualties may impact the number of lives saved. Therefore, it is essential that members of the public surrounding the scene, or those who are directly caught up in the event, can act as the first responders, if safe to do so, providing they have had some degree of training or prior knowledge. Furthermore, there are additional challenges when the 'normal' response chain, in which professional first responders are summoned to the incident site and arrive promptly, is broken. Responders may be prohibited from reaching the casualties due to the location being difficult to access, because they cannot access the casualties without putting themselves in danger, or due to hostage situations in which terrorists actively deny access to the incident site. Perhaps current thinking on the response to terrorism needs to be modified. At times the affected crowd may need to fend for itself, drawing on resources, knowledge and skills that exist within the crowd itself.

\section{Distinctions between the 'Crowd' and the 'Public'}

It is important to highlight the difference between the 'public' and the 'crowd'. The public refers to the UK population in general and assumes that any crowd comprised largely of the 'public' will be typical of it. For example, if within the population as a whole approximately 2 percent have received formal first aid training at some stage of their lives, it can be assumed that this figure will be mirrored within any crowd, unless there is reason to assume that the individuals comprising that crowd are unrepresentative of 'the public' as a whole. Whereas 'the public' at the scene of the Tavistock Square bus bombing on 7/7 was not typical of the public, as the bomb exploded outside the British Medical Association where a meeting was taking place - full of individuals with a level of medical training, although different to what was required at the scene.[1]

The 'crowd' refers to the mass of individuals caught up in the incident itself. Usually 'the crowd' largely comprises of members of the public, yet there may be some individuals who have skills and roles specific to the situation depending on the location. For example, on-duty stewards and first 


\section{Journal of Terrorism Research}

aiders at a sporting event, concert or festival or security staff at a large shopping centre. This 'crowd' correlates to the 'community of circumstance' and is identified within the current community resilience policy of the UK government's Civil Contingencies Secretariat, which shares a commonality only for the duration of the incident, in contrast to a 'community of interest'. The 'community of interest' may include worshipers of a local synagogue, mosque or church, members of a sport team or a community defined by geographic location, both of which share a common identity outside of the incident.[2]

\section{New Threats: Crowded Places}

The 21 st Century marked a significant focus of the UK's approach to responding to the increased threat of terrorist attacks in crowded places, strengthening physical security by building barriers to entry and increasing the screening technology at airports in particular. Incidents such as the two failed car bombings during the summer of 2007 at the Tiger Tiger nightclub in London's Haymarket and the Jeep laden with propane gas which failed to detonate at Glasgow City Airport have catalysed the strengthening of physical security. Aside from the fact that the propane gas failed to detonate, it was the security bollards at Glasgow City Airport that prevented the Jeep from gaining entry to the airport.[3]

These attacks and others such as the Mumbai bombings of 2008 and 2011, cemented understanding that crowded places are becoming increasingly popular targets for Islamist attackers, [4] prompting the then Prime Minister Gordon Brown to commission Lord West of Spithead, then Home Office Parliamentary Under-Secretary of State for Security and Counter-Terrorism. Lord West made two fundamental recommendations. Firstly, in the short term there was a need for increased physical security around crowded areas and that physical resilience against terrorism was dependent on engaging with a wide range of local partners, including local authorities and businesses. Secondly, a more long-term approach to protection has been provided by the Centre for the Protection of National Infrastructure (CPNI). The agency runs free briefings and training courses for architects, engineers, planners, designers and other built environment stakeholders to encourage the strengthening of existing hard security measures. The CPNI also provides additional general security advice to businesses and the private sector.[5]

\section{Initial Response: A Panicked or an Effective Crowd?}

When assessing some of the 21 st Century mass casualty terrorist attacks it is clear that the initial chaos following such attacks means that information flow can be difficult in the immediate aftermath. It can take time to establish exactly what type of incident has occurred, which emergency service is required and how many. It is also possible that even once information has reached the necessary channels that the emergency services can be delayed before reaching a scene, or the injured. This is what happened at the Hillsborough Football Stadium disaster in 1989. When the Hillsborough Disaster took place, it was not yet routine for emergency services, such as ambulance paramedics, to be present at the football stadium, although police officers were present. The police officers on site were excellent at dealing with rowdy fans and pitch invasions, as they still are today. However, they had limited first aid skills and were ill-equipped to assist or assess the casualties. The lessons taken from the Hillsborough Disaster have resulted in practical changes, such as a larger emergency services presence at today's sporting events and music festivals, and the like. There is also an increase in the number of stadia staff that under go first aid training, and the 


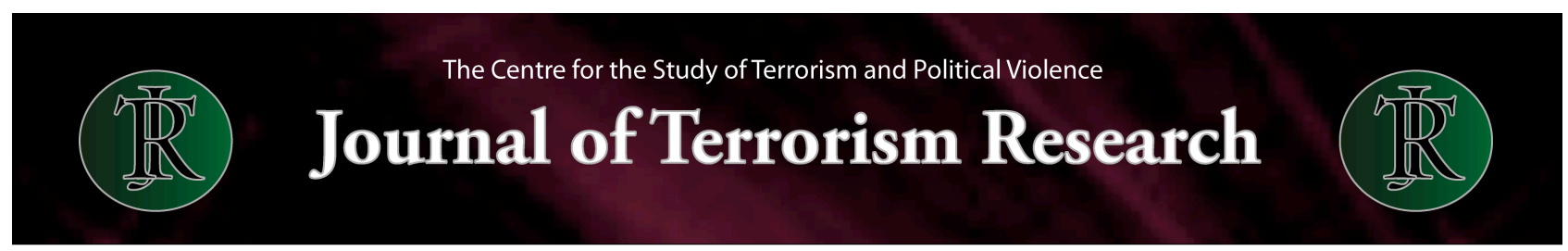

presence of volunteer first aiders are required, which is certainly the case for the London 2012 Olympics.

It is clear that there have been marked changes in the approach to protecting against 21st Century mass casualty attacks. However, whilst the building of resilient infrastructure helps the response and prevention of successful acts of terror, it is also fundamental that civilians protect themselves. There are various views on the psychological state of mind of the population and their effectiveness in responding to an incident.

Richard La Piere suggested that "Danger may turn a passive audience into a shrieking, milling mass which clogs the aisles and jams the exits".[6] Historically, there has been the prevailing view that mass hysteria encompasses groups in times of crisis, with people often adopting Darwinian characteristics where individual survival would become the only priority at the expense of the crowd. In essence the belief was that the crowd would fall into mass panic therefore being of no assistance in a time of crisis, a hindrance rather than a help. John Drury sums up the premise of mass panic theorists. He suggests that they conclude 'human reactions to emergencies ... lead to more problems (e.g. fatalities) than the danger that people are trying to escape from'.[7] Later theories explored the notion that actually in an emergency situation the public do not panic, instead they can make rational decisions that seek to garner the best possible outcome. For example, Mintz argued that individuals seek to be compliant in a crowd as long as the entire crowd cooperates.[8] However, once someone seeks to act individually and gains a benefit from that action it makes no sense for the rest of the crowd to continue acting cooperatively, as they will be disadvantaged. Thus what appears to be mass panic may be a reflection of calculated risk, selfishness and individualism become the rational responses but make the concept of the crowd as zero responders difficult to comprehend.[9]

Most recently, academic studies and other evidence has suggested that solidarity and communal spirit appears to be far more prevalent than previously thought. For example, during the Hillsborough disaster, football fans trapped in the pens helped each other to 'unofficial emergency exits' over two-metre high fences.[10]

Another example of camaraderie amongst crowds came from Davinia Douglass, whose face was severely injured by one of the 7/7 explosions. Davinia gave evidence in a written statement which explained that her fellow passengers gave her immediate assistance and led her from the bombed carriage.[11] Stephen Huckleberry has been honoured since his heroic efforts in the aftermath of the bombings by assisting his fellow passengers, after only one day of first aid training. Recognising that he had some skills, he felt compelled to assist.[12]

\section{Historical Responders}

It is evident that if a crowd can help themselves following an emergency situation, lives may be saved. Providing society with the skills and knowledge required to administer immediate response prior to the arrival of the professional responders is nothing new. During the Second World War, an extensive self-help attitude was adopted in the UK. The population took on public safety roles to respond to incidents caused by German bombing raids, including fire wardens and air raid wardens. [13] By March 1944, more than 1.5 million men and women where volunteering for home defence roles and an additional 5 million citizens were legally required to serve 48 hours a month as fire wardens.[14]

Sherer suggests that the reasoning behind an individual's decision to volunteer is due to contextual variables in the environment of the said individuals' social background, personality, situation and 


\section{Journal of Terrorism Research}

social participation.[15] It is also suggested that the initial motivation to volunteer is due to the process of socialisation, as a result of ethnic and religious factors and due to self-perception and social expectations.[16] Notably, during the Second World War, risk and danger was widely recognised and accepted and in turn encouraged people to volunteer. Therefore in the UK it is clear that a widely accepted and believed risk may be needed before the public will volunteer their services and take an active role in resilience.

Though the UK's volunteer network began to swell following the Munich Pact, in 1938, it was not until credible new threats (such as the Korean War and the 1962 Cuban Missile Crisis) that volunteer numbers really increased. More recently, hurricane warnings issued to New Orleans, following the wake of Hurricane Gustav, resonated with residents who had personal experience with previous events and were more willing to believe that action was necessary.[17]

In the US for example, many volunteers receive first aid training, yet this is not something that has been given much priority in the UK, despite our long history of IRA attacks. The government attempts to draw in the private sector to assist with the response and resilience to terror attacks through initiatives such as, Project ARGUS (Area Reinforcement Gaining Used Scenarios) a project devised by the National Counter Terrorism Security Office (NaCTSO). It aims to raise awareness of counter terrorism issues amongst businesses and make communities more resilient to attacks by creating training packages focusing on safe evacuations of large venues.[18] Another project is Project Griffin, a police initiative to protect cities and communities from the threat of terrorism. It brings together, and coordinates, the resources of the police, emergency services, local authorities, businesses and private sector security industry in order to assist the police with evacuation procedures.[19] However, neither programme offers first aid training, despite the fact that they are perfect forums for teaching such skills. Nevertheless, the training and awareness they provide are fundamental components to building a responsive and resilient society.

The UK is virtually the only country in the European Union where training in first aid skills is not a compulsory part of the school curriculum. Despite its fundamental usefulness, first aid has only recently been added to schools (if at all) as a result of lobbying by the British Red Cross' campaign, 'Life. Live It', which forms part of the optional subject Personal, Social and Health Education. However the subject does not lead to a qualification and is therefore not at the top of the agenda for most schools.[20]

Whilst not specifically related to terror, Rosanna Briggs, Deputy Head of Emergency Planning at Essex County Council, devised a five day educational programme, known as the 'What if' campaign which can be altered according to individual school requirements and provides educational learning for school children helping them build response skills and resilience to emergency situations. The scheme has proven successful in its outreach to children however it is yet to tackle the engagement of young adults, partly due to funding as studies show that engaging children is far more effective than attempting to engage young adults.[21] Nevertheless, children carry the messages home and encourage response and resilience preparedness to take place when engaging their parents.[22] At the end of the five day programme the children were questioned about their experience. Statistics show that 82 percent of children felt more prepared to respond to an emergency, 78 percent of children knew what a risk centre was and 96 percent knew what a 'grab bag' was.[23] This level of responsiveness is a key stage in building a resilient and responsive civilian population for their generation.

The London Fire Brigade (LFB) has also put programmes in place to help train and build a resilient civilian population. In 2002 the LFB successfully set up the Local Intervention Fire Education (LIFE) programme in response to the poor relations with the community in Tower Hamlets, where 


\section{Journal of Terrorism Research}

fire-fighters experienced frequent physical and vocal abuse from the locals.[24] The LFB's LIFE programme has since expanded to nine teams across London, running 260 LIFE courses and benefiting around 3000 young people from most of London's boroughs.[25] Engagement with young people is fundamental to building a resilient and responsive society, regardless of the threat. The success of LIFE has resulted in its implementation nationally and in New Zealand.[26] Engaging civil society in this way facilitates relationships between local communities and their fire services which are vital, particularly in an emergency. Although not first aid, the programme provides lessons of responsibility, danger awareness and the importance of the role the Fire Service provides for the youth of today. The question is, is this enough?

Health and Safety guidelines, at present, require just one qualified first aider per 100 employees in low risk environments and only one in 50 for environments deemed to be moderate or high risk.[27] At present, only around one in every 200 members of the UK population holds a current valid first aid certificate and around 95 percent have never had any formal first aid training. Yet, the benefit of embedding first aid knowledge within the population is clear. Immediate treatment is vital in preventing death from traumatic injury, particularly the severe bleeding from traumatic amputations and penetration injuries that are common effect of the type of explosive devices that are favoured by both the IRA and Islamist-inspired activists.

\section{Israel - A Responsive and Resilient Population}

The value of first aid skills is also well understood in Israel, where suicide bombers have detonated numerous devices in crowded places such as markets and nightclubs. Years of experience has created a resilient country and community that continuously improve their emergency services techniques, through lessons learned rather than forward planning, due to the exponential threat, and volumes of previous incidents to learn from.[28] As a result, Israeli emergency response frameworks are heavily focused on casualty management and this has led to a number of particularly interesting approaches. These include national drills that consider chemical, biological, radiological and nuclear (CBRN) response exercises in which the entire population takes part, such as Israel's fifth home front command drill last year, Turning Point 5. At least one of those scenarios will entail sustained rocket attacks on the Tel Aviv region, a geriatric hospital and/or the electrical power grid. In addition, Knesset members will also be expected to respond to a simulated attack on the Knesset in Jerusalem. However, even where the risk/threat is recognised and present, the population becomes complacent.

Israel's quick response to attacks is aided by the knowledgeable population and interoperability of the emergency services. In particular, there is a strong focus on what is known in Israel as 'market forces'. This is the ability of the general public to provide assistance to those injured in the attack with whatever resources are to hand. For example, the suicide attack on April 12 2002, saw a female suicide bomber detonate in the busy Machane Yehuda market in Jerusalem. The market was crowded with people, and in response to the incident, market traders and customers cleared tables to be used as stretchers.[29] This level of response is fundamental to Israel's formation of a resilient community, as particularly in this case, the narrow alleys that surrounded the area hampered the evacuation of the wounded, and consequently without the assistance of the bystanders, the response would not have been so rapid or life-saving.[30]

Aside from the basic rules of methodology and protocol, there is a general consensus that Israel's emergency services are able to facilitate a quick response as a result of their flexibility. Aside from the structured planned response, there are allowances made for decision-making at the ground level, as often individuals are in situations where they have to make their own decisions without seeking 


\section{Journal of Terrorism Research}

advice from their seniors.[31] This level of responsibility adds to the fluid functionality of the response and the services ability to react as quickly as possible, which in turn creates an environment for building national resilience.

Naturally the involvement of the population raises concern as to whether they are experienced in perceiving secondary threats or not. However, experience creates a society that is not built on heroism but on safety and security. The population is alert and aware, and they are able take on roles that free up the first responders, which include: first report, first rescue, stretcher-bearers, and emotional support.[32]

Professor Isaac Ashkenazi of disaster medicine at Ben-Gurion University articulates an optimum level of response, which helps the community bounce back from a traumatic event. "In 20 minutes you clear the site of victims. In 60 minutes, all victims are treated in hospital. In three hours the area is completely clean of flesh and blood, but more important, in four days the area should be completely reconstructed."'[33] The goal is to send a message to the perpetrators that even if the population is traumatised, they promote an image of 'business as usual.'

In recent years, this ability to harness a 'market forces' response has been formalised through the Multi-Casualty Response Vehicles (MCRV) owned by Magen David Adom (MDA), the Israeli Emergency Medical Service. When MDA was called to respond to a multi-casualty incident it sends MCRV, along with ambulances and paramedics. This model works in Israel because first aid is recognised to be very important due to its utility during mass casualty incidents, as suicide bombings are common and therefore such a response is actioned frequently.

\section{Arming the Public}

The Strategic Defence and Security Review cuts may result in sufficient cuts to frontline emergency services. Therefore the voluntary sector services such as St John's Ambulance, British Red Cross and Metropolitan Police Special Constables may be increasingly relied upon to deal with periods of high-volume call-outs. The role of existing Community First Responders - a Department of Healthrun scheme in which local volunteers respond to 999 calls reporting heart attacks and treat patients until professional first responders arrive - may need to be expanded, with some local ambulance trusts needing to rely on them more heavily and for a wider range of assistance. First aid and casualty management training currently given to Special Constables could also be expanded to help them deal with mass casualty incidents.

The British Red Cross provides over 462 vehicles across the UK and much like St John's Ambulance, they support our emergency planning and response roles. The vehicles include: ambulances, fire and emergency support service vehicles, vans, coaches, people carriers and quad bikes. The British Red Cross work with the Fire Brigade by providing victim support to the fire service with emergency vehicles equipped with food, a shower, toys, a fridge, and clothes. The vehicles are essential, assisting the habitants, whose home is being extinguished in recovering from the initial shock and preparing them for the next step, be it returning to their homes or awaiting the council appointed temporary shelter.[34]

At present, there is the assumption that a conventional model of attack will comprise of an explosion, followed by a 999 (emergency) call, which summons professional responders to the scene. When a less conventional attack takes place, such as mass casualty incidents, the normal response chain can become broken or interrupted and this is where the complexities are likely to increase. For the UK to be sufficiently resilient to the threat of suicide terrorism current responsive training, resources and even basic first aid, needs to be extended beyond professional first 
responders to ensure that the resources needed to deal with a mass casualty incident are readily available. Furthermore, there needs to be an acceptance that the affected crowd is frequently capable of taking a proactive role in the response, particularly if previously exposed to the right tools, for example a first aid course.

\section{Conclusions}

It is evident that even if a percentage of the crowd can act as a zero responder, those requiring immediate medical assistance could be given an increased chance of survival. Previous mass casualty incidents provide us with many lessons and can uncover benefits of seeing the crowd as a potential solution, rather than part of the problem. It is worth noting that, despite their ability and efficiency, professional responders are unable to arrive at the scene of a major incident instantaneously. The sheer logistics of having to call them, awaiting dispatch, travel to the scene, all takes time and this does not take into consideration traffic, managing equipment and the safety assessment of the scene. Further delays also occur if attacks take place simultaneously, or in close succession, as they did in Madrid in 2004 and in London in 2005.

It is essential that the 'public' and therefore the 'crowd' develop the skills to be safety aware primarily and then become responsive and resilient in any emergency situation. The Scottish Ambulance Services are training their society by developing resilience in local communities to help manage major day-to-day challenges. In 2011 the Service developed a Strategy for Community Resilience, which is committed to strengthening the partnership by working with community members, NHS Boards and the wider NHS, other statutory services, Volunteer Development Scotland and the voluntary sector to support and foster community resilience. This strategy sets out how the Service will take this forward. By providing the general public and subsequently the 'crowd' with the skills, knowledge and training to assist in future attacks. This may become a very important resource in responding to future terrorist attacks or any kind of emergency situation.

During a major incident, the affected crowd or community needs to come together and assist where necessary in order to free up the essential emergency services, so that they can focus on the most severely in need. This form of self-reliance is a model of unified assistance that has proved effective in UK previously, for example during the Second World War.

\section{Problems}

At present in order to achieve a quick response to mass casualty incidents the 'crowd' must have some knowledge, as well as the blue light services having extensive interoperable training, to ensure fluidity. Budgets restrict that. However, a centralised governmental committee that pools resources of the blue light services to make time and funds available solely for interoperable training may be a solution. Effective communication during an emergency is also a challenge, therefore utilising the media is essential. The emergency services require media training. Furthermore it is fundamental that the services build relations with the media so that they can be relied upon to deliver accurate and productive messaging to the civilian population. Finally, society today is lacking education in first aid, response and resilience, there is a lack of desire to engage. Therefore it is essential that education starts from the bottom, up. Educating children at school and providing lessons for them to take home to their parents is an effective method of educating the parents. Additionally, incorporating first aid training into existing training for special constables, project ARGUS and project Griffin would also be exceptionally beneficial. Finally, utilising the 


\section{Journal of Terrorism Research}

skills and services of the voluntary sector is essential, be it military veterans or volunteer organisations such as the British Red Cross or St John's Ambulance.

About the Author: Montine Walters first became interested in this area having trained and served with the Israeli National Ambulance Service, Magen David Adom. Montine worked within the United Nations Office for Disarmament Affairs in New York prior to graduating with a Distinction for her Master's in Intelligence and International Security, from the department of War Studies at King's College London. During her Master's Montine enjoyed interning with numerous think tanks including the Royal United Services Institute within the National Security and Resilience department. Montine has since worked as a Risk and Security consultant for Diligence LLC and is now enjoying a role with the Greater London Authority as an Olympic Resilience Officer. Montine enjoys working within the risk and security field, understanding threats and building resilience, and hopes to further nurture her interests in crisis management, resilience, protective and business intelligence, threat analysis, business continuity, travel security, public safety and terrorism.

\section{Notes:}

[1] Cole, Jennifer, Walters, Montine, \& Lynch, Mark. (2011) 'Part of the Solution, Not the Problem: The Crowd's Role in Emergency Response', Contemporary Social Sciences: Journal of the Academy of Social Sciences, 6 (3): 362-375.

[2]Cole, Jennifer, Walters, Montine, \& Lynch, Mark. (2011) 'Part of the Solution, Not the Problem: The Crowd's Role in Emergency Response', Contemporary Social Sciences: Journal of the Academy of Social Sciences, 6 (3): 362-375.

[3] Townsend, Mark, Revill, Jo \& Kelbie, Paul. (2007) 'Terror threat 'critical' as Glasgow attacked', The Observer, [Online], Available at: http://www.guardian.co.uk/uk/2007/jul/01/terrorism.world2.

[4] Bell, Sandra. (2007) 'Car bombs: inside vehicle borne improvised explosive devices (VBIEDs)'. RUSI Analysis Commentary. [Online], Available at: http://www.rusi.org/analysis/commentary/ref:C468A125C1E6E1/\%3E/.

[5] Government, HM. (2010) 'Crowded Places: A Response to the Consultation. [Online], Available at: http://www.nactso.gov.uk/ SiteCollectionDocuments/AreasOfRisk/crowded-places.pdf/.

[6] Chertkoff, Jerome. \& Kushigian, Russell. (1999) 'Don't Panic: The Psychology of Emergency Egress and Ingress'. Praeger: Abingdon.

[7] Drury, John. (2011) 'Collective Resilience in Mass Emergencies and Disasters: A Social Identity Model'. In: Joland Jetten, Catherine Haslam \& S. Alexander Haslam (Eds) The Social Cure: Identity, Health, and Well-Being’. Psychology Press: Hove.

[8] Mintz, Alexander. (1951) 'Non-Adaptive Group Behaviour'.Journal of Abnormal and Social Psychology, 46(2), 150-159.

[9] Cole, Jennifer, Walters, Montine, \& Lynch, Mark. (2011) 'Part of the Solution, Not the Problem: The Crowd's Role in Emergency Response', Contemporary Social Sciences: Journal of the Academy of Social Sciences, 6 (3): 362-375.

[10] Drury, John, Cocking, Chris. \& Reicher, Steve. (2009) 'Everyone for Themselves? A comparative study of crowd solidarity among emergency survivors'. British Journal of Social Psychology, 48 (3):487-506.

[11] Coroner, HM. (2011) Coroner's inquest into the London bombings of 7 July 2005. [Online], Available at: http:// 7julyinquests.independent.gov.uk.

[12] Topping, Alexandra. (2010) 'Coroner tells hero of 7/7 London bombing, 'Your actions were amazing”. Guardian Online. [Online], Available at: http://www.guardian.co.uk/uk/2010/nov/10/coroner-77-london-bombing-hero

[13] Holgate, Joan. (2004) 'The Night of the Baked Potatoes'. BBC WW2 People's War. [Online], Available at: http:// www.bbc.co.uk/ww2peopleswar/stories/08/a2785908.shtml. 


\section{Journal of Terrorism Research}

[14] Woolven, Robin. (2008) 'UK Civil Defence in Historical Perspective, in: Jennifer Cole (Ed.) Civil defence and Emergency Response, RUSI Workshop Report, London, 15-20.

[15] Sherer, Moshe. (2004) 'National Service in Israel: Motivations, Volunteer Characteristics, and Levels of Content', Non-profit and Voluntary Sector Quarterly, March 2004, 33 (4):94-108.

[16] Raviv, A., Bar-Tal, D., Raviv, A., \& Fleissig, P. (1987) 'Understanding motivation to help: A study of social cognition'. Genetic, Social and General Psychology Monographs, 113 (3):323-334; Schneider, John C. (1996). 'Philanthropic styles in the United States: Toward a theory of regional differences', Non-profit and Voluntary Sector Quarterly, 25 (2):190-210; Gidron, Benjamin., \& Lazar, Alon. (1998) 'Level of religiosity and patterns of giving and volunteering in Israel', Social Security, 52:44-56.

[17] Cole, Jennifer. (2008) 'Exploring the Emergency Response', in: Jennifer Cole (Ed.) Civil defence and Emergency Response. RUSI Workshop Report, London, 7-12.

[18] National Counter Terrorism Security Office, 'Project Argus'. [Online], Available at: http://www.nactso.gov.uk/OurServices/ Argus.aspx.

[19] City of London Police, 'Project Griffin'. [Online], Available at: http://www.cityoflondon.police.uk/CityPolice/Departments/CT/ ProjectGriffin/; Project Griffin, 'Protecting our Communities'. [Online], Available at: http://www.projectgriffin.org.uk/

[20] British Red Cross (2011) 'Life. Live it. First Aid Campaigns'. [Online], Available at: http://www.redcross.org.uk/What-we-do/ First-aid/First-aid-campaigns/.

[21] Briggs, Rosanna. (2011) 'Building Children's Resilience and Response Capabilities', Interview conducted by Montine Walters, 25.08.2011, London, UK.

[22] Mackenzie, Mandy. (2011) 'UK Response and Resilience - Perspective of the High Impacts Team Policy Manager within the Civil Contingencies Secretariat', Interview conducted by Montine Walters, 25.08.2011, London, UK.

[23] Briggs, Rosanna. (2011) 'Building Children's Resilience and Response Capabilities', Interview conducted by Montine Walters, 25.08.2011, London, UK.

[24] UK Parliament Online, 'Local Intervention Fire Education (LIFE) Programme in the London Borough of Tower Hamlets', Office of the Deputy Prime Minister, Housing, Planning, Local Government and the Regions. [Online], Available at: http:// www.publications.parliament.uk/pa/cm200203/cmselect/cmodpm/1060-ii/1060we35.htm

[25] London Fire Brigade, 'Local Intervention Fire Education (LIFE)'. [Online], Available at: http://www.london-fire.gov.uk/ LocalInterventionFireEducation.asp.

[26] Higgens, Bernie. (2011) 'London's Response and Resilience - Perspective of the Head of Operations for the London Fire Brigade', Interview conducted by Montine Walters, 12.08.2011, London, UK; London Fire Brigade, 'Local Intervention Fire Education (LIFE)'. [Online], Available at: http://www.london-fire.gov.uk/LocalInterventionFireEducation.asp.

[27] Cole, Jennifer. (2009) 'Medical Equipment Available in the Aftermath of Terror Attacks'. Emergency Services Times, May, 2667.

[28] Mizrahi, Ilan. (2011) 'Israel's Response and Resilience - Perspective from the former Head of the National Security Council in Israel and former Deputy Head of Mossad', Interview conducted by Montine Walters, 21.06.2011, Ramat Aviv, Israel.

[29] Perlinger, Arie, Pedahzur, Ami, Zalmanovitch. (2005) 'The Defensive Dimension of the Battle against Terrorism - An Analysis of Management of Terror Incidents in Jerusalem', Journal of Contingencies and Crisis Management, 13 (2):79-91; Rafalowski, Chaim. (2011) 'Magen David Adom - Israel's Emergency Ambulance Service take on Response and Resilience', Interview conducted by Montine Walters, 27.06.2011, Tel Aviv, Israel.

[30] Rafalowski, Chaim. (2011) 'Magen David Adom - Israel's Emergency Ambulance Service take on Response and Resilience', Interview conducted by Montine Walters, 27.06.2011, Tel Aviv, Israel.

[31] Richman, Aaron. (2011) 'Israel's Response and Resilience', Interview conducted by Montine Walters, 20.06.2011, Tel Aviv, Israel. 
The Centre for the Study of Terrorism and Political Violence

\section{Journal of Terrorism Research}

[32] Richman, Aaron. (2011) 'Israel's Response and Resilience', Interview conducted by Montine Walters, 20.06.2011, Tel Aviv, Israel.

[33] Weiner, Robert. (2009) 'Israeli's share expertise in responding to terror', New Jersey Jewish News, [Online], Available at: http:// njjewishnews.com/njin.com/072309/njIsraelisShareExpertise.html

[34] Wood-Heath, Moya. (2011) 'UK's Response and Resilience - Perspective of the Emergency Planning and Civil Protection Advisor to the Red Cross', Interview conducted by Montine Walters, 11.08.2011, London, UK. 